Rapid Communication

\title{
Influence of aggregated morphology on carbon dioxide uptake of polythiophene conjugated organic networks
}

\author{
Shanlin Qiao ${ }^{\mathrm{a}, \mathrm{b}}$, Zhengkun Du ${ }^{\mathrm{a}}$, Wei Huang ${ }^{\mathrm{a}}$, Renqiang Yang a,* \\ ${ }^{a}$ CAS Key Laboratory of Bio-based Materials, Qingdao Institute of Bioenergy and Bioprocess Technology, Chinese Academy of Sciences, Qingdao 266101, China \\ ${ }^{\mathrm{b}}$ University of Chinese Academy of Sciences, Beijing 100049, China
}

\section{A R T I C L E I N F O}

\section{Article history:}

Received 21 October 2013

Received in revised form

16 December 2013

Accepted 28 December 2013

Available online 8 January 2014

Keywords:

Pore organic polymer

Polythiophene

Steric configuration

Aggregated morphology

Carbon dioxide adsorption

\begin{abstract}
A B S T R A C T
Two novel thiophene-based conjugated networks CMPs-TTT and CMPs-DTBT were designed and prepared with different steric configuration building blocks by $\mathrm{FeCl}_{3}$ oxidative coupling polymerization. UV-vis spectra, FE-SEM and TEM images showed CMPs-TTT and CMPs-DTBT having the different aggregated morphologies. After porous analysis and gas adsorption test, the result showed $\mathrm{CO}_{2}$ uptake capacity of CMPs-DTBT with amorphous aggregation model is 2.88 times and 2.66 times greater than that of CMPs-TTT with large lamellar structure model at $273 \mathrm{~K}$ and $298 \mathrm{~K}$ (1.0 bar), respectively. As a result, this communication proved that change the topological structure of the polymer can influence the $\mathrm{CO}_{2}$ adsorption capacity significantly.
\end{abstract}

(c) 2014 Elsevier Inc. All rights reserved.

\section{Introduction}

Rapid consumption of hydrocarbon fuels had caused $\mathrm{CO}_{2}$ concentration increased quickly in the atmosphere. It is well known that $\mathrm{CO}_{2}$ is probably the main contributor to the global-warming and climate change. Most countries had drawn much manpower and financial resources in this problem last few decades [1]. In a long-term, the best strategy to lower $\mathrm{CO}_{2}$ emissions is to adopt new energy solutions which do not produce $\mathrm{CO}_{2}$ as a byproduct, however, this envisaging is not practical nowadays, because there is no any new energy reserves combining with technology can substitute the low-price fossil fuel (coal, petroleum and natural gas). $\mathrm{CO}_{2}$ capture and storage provides humanity a potential resolution to the fossil energy used continually without $\mathrm{CO}_{2}$ release in the short-term until green energy technologies mature [2,3]. A wide range of $\mathrm{CO}_{2}$ adsorbents have been reported including zeolites [4,5], carbons [6,7], metal organic frameworks (MOFs) [8,9] and microporous organic polymers (MOPs) [10,11].

Organic porous polymers skeleton comprised of light, non-metallic elements with high chemical and thermal stability had exhibited potential application in $\mathrm{CO}_{2}$ uptakes. Various organic reactions have been exploited to synthesize microporous polymers such as hypercross-linked polymers (HCPs) [12,13], polymers of intrinsic microporosity (PIMs) [14,15], covalent organic frameworks (COFs) [16]. Conjugated microporous polymers (CMPs) [17-19] is a new class

\footnotetext{
* Corresponding author. Tel.: +86532 80662700; fax: +8653280662778.

E-mail address: yangrq@qibebt.ac.cn (R. Yang).
}

of pore materials which are prepared by transition metal coupling chemistry, such as palladium-catalyzed Stilling, Suzuki, SonogashiraHagihara coupling condensation reaction and other oxide coupling reaction. The unique feature of CMPs is that they combine the stiff pore structure and conjugated electron system in one bulk material which show good performance in gas storage and separation. Weber and Thomas [20], Yuan et al. [21], and Chen et al. [22] reported a series of polyfluorene microporous polymers with Brunauer-Emmett-Teller (BET) areas from $450 \mathrm{~m}^{2} \mathrm{~g}^{-1}$ to $1043 \mathrm{~m}^{2} \mathrm{~g}^{-1}$ and the highest $\mathrm{CO}_{2}$ uptake reached to $12 \mathrm{wt} \%$ at $1.0 \mathrm{bar}, 273 \mathrm{~K}$. Schmidt et al. [23], reported the polythiophene microporous conjugated polymers with BET area up to $1056 \mathrm{~m}^{2} \mathrm{~g}^{-1}$, however, no $\mathrm{CO}_{2}$ adsorption data was given. Recently, Chen et al. [24] reported the microporous polycarbazole CMPs with BET area up to $2220 \mathrm{~m}^{2} \mathrm{~g}^{-1}$ and the $\mathrm{CO}_{2}$ uptake capacity as high as $21.2 \mathrm{wt} \%$ at $273 \mathrm{~K}, 1.0$ bar. Kanatzidis [25-27] reported a series of new conjugated polymers for gas capture which $\mathrm{CO}_{2}$ uptake can be up to $18 \mathrm{wt} \%$ near atmospheric pressure at $273 \mathrm{~K}$. However, the relationship of steric structure of monomer with gas adsorption got little attention.

In this communication, we focused on the relationship between configuration of the building blocks (or starting monomers) with $\mathrm{CO}_{2}$ adsorption capacity on the networks which has different aggregation morphology caused by the steric configuration of the building block. Two thiophene based networks CMPs-TTT and CMPs-DTBT have been prepared and with different aggregation morphology caused the $\mathrm{CO}_{2}$ isosteric enthalpies has much discrepancy although the two networks with identical chemical component and similar BET areas and pore structure. 


\section{Results and discussion}

Efficient $\mathrm{CO}_{2}$ adsorption depends on the surface area, pore structure, and chemical functionality of the material [28]. The building blocks show great influence on the above three parameters, thus, design and/or selection of specific monomer is very important. In this work we chose thiophene as the chemical unit to structure the following reasons, (1) the electron-rich thiophene conjugated aromatic system (Lewis-base) may have the strong interaction with $\mathrm{CO}_{2}$ molecules (electron-poorer, Lewis-acid), (2) the lone pair electrons of heterocyclic sulfur atom on the pore surface can provide dipole-quadrupole interactions sites with $\mathrm{CO}_{2}$ [29]. The two core building blocks TTT (nonplanar propeller-like) and DTBT (right-angle) are made up of thiophene rings and show different steric configuration (Scheme 1). The single crystals structures show that each thiophene ring in the TTT unit is chiral due to a twist through the center thiophene plane, the three $\alpha$-conjugated rings are quasi-coplanar (torsional angles $=21^{\circ}$ and $15^{\circ}$ ), the other two thiophene rings in the $\beta$-positions of the central unit are nearly perpendicular to the average plane of the more conjugated sequence $\left(93^{\circ}\right.$ and $\left.80^{\circ}\right)$ [30]. The crystallographic structure of DTBT represents a pseudo-tetrahedral 3D conjugated architecture, the two thiophene rings attached at the 3- and $3^{\prime}$-positions of bithiophene produce a dihedral angle close to $90^{\circ}$ between the two thiophene rings that form the 2,2'-bithiophene [31]. The two thiophene-based networks CMPs-TTT, CMPs-DTBT were straightforward synthesized by $\mathrm{FeCl}_{3}$ oxidative coupling polymerization at room temperature shown in Scheme 1. This method gave high yield and the single building block used in polymerization process can avoid the effect of other structure on the morphology. The crude polymers were washed with methanol and concentrated hydrochloric acid, then, Soxhlet extraction with methanol and tetrahydrofuran for $24 \mathrm{~h}$ gave yield more than $90 \%$ (CMPs-TTT, dark red solid; CMPs-DTBT, brownish solid). The insoluble solid was characterized by FT-IR (Fig. 1a) and ${ }^{13} \mathrm{C} \mathrm{CP-}$ MAS NMR (Fig. 1b). One can observe that the signal at 1663$1669 \mathrm{~cm}^{-1}$ was assigned to the $\mathrm{C}=\mathrm{C}$ stretching vibration in the thiophene ring and $1220 \mathrm{~cm}^{-1}, 1090 \mathrm{~cm}^{-1}$ was the stretching vibration of $\mathrm{C}-\mathrm{S}-\mathrm{C}$. The ${ }^{13} \mathrm{C}$ CP-MAS NMR signals of carbon chemical shift in the range of $115-150 \mathrm{ppm}$ are related to the thiophene carbon atoms of building block.

The porosity structural parameters of CMPs-TTT and CMPsDTBT were measured by adsorption analysis using nitrogen as the probe molecule at $77 \mathrm{~K}$. Fig. 2 shows the $\mathrm{N}_{2}$ adsorption-desorption isotherms for the two polymers and they give similar BET surface area with $57.72 \mathrm{~m}^{2} \mathrm{~g}^{-1}$ and $62.97 \mathrm{~m}^{2} \mathrm{~g}^{-1}$, respectively. The building blocks of CMPs-TTT and polycarbazole network CPOP-1 have the similar propeller-like configuration, however, the BET surface area of CPOP-1 is up to $2220 \mathrm{~m}^{2} \mathrm{~g}^{-1}$, the much lower BET for CMPs-TTT

a

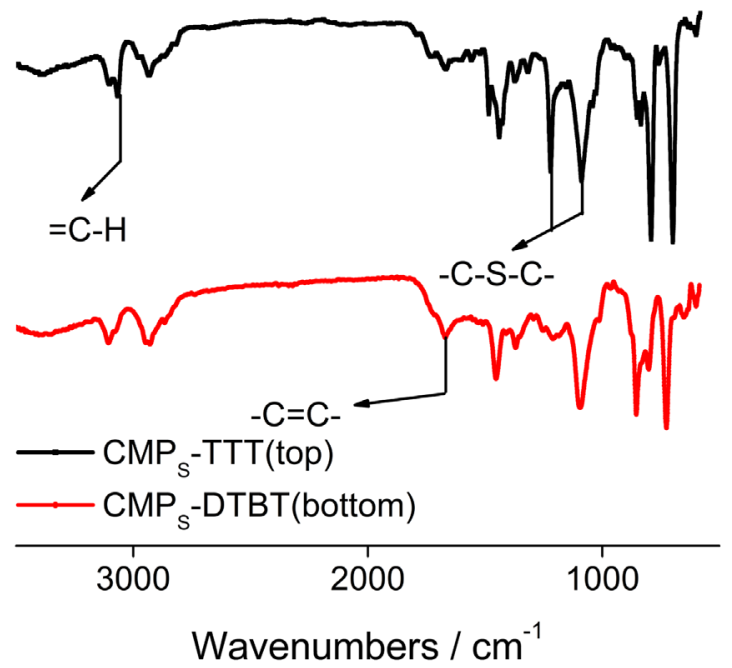

b

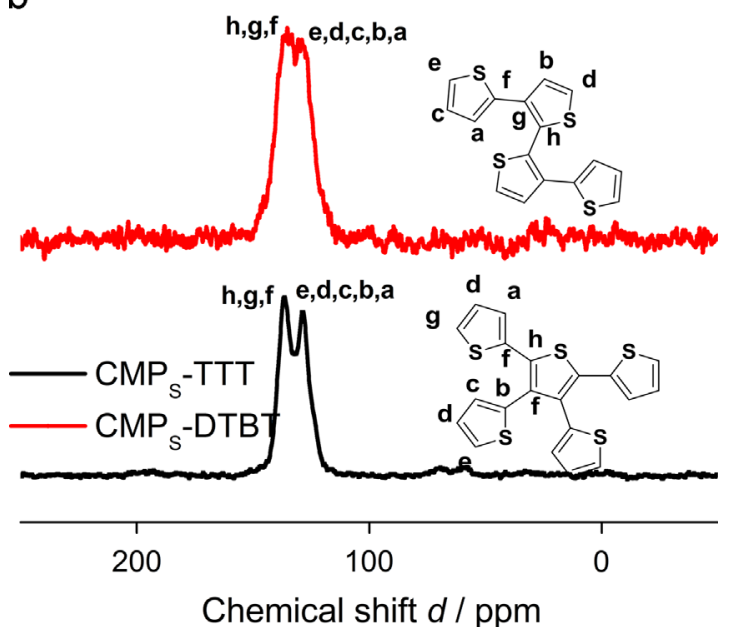

Fig. 1. (a) FT-IR spectra and (b) ${ }^{13} \mathrm{C} C \mathrm{CP}-\mathrm{MAS}$ NMR spectra of the two networks CMPs-TTT and CMPs-DTBT. (For interpretation of the references to color in this figure legend, the reader is referred to the web version of this article.)<smiles>Brc1sc(Br)c(Br)c1Br</smiles>

TTT<smiles>CC(C)(C)c1ccc(-c2sc(-c3ccc(C(C)(C)C(F)(F)F)s3)c(-c3ccc(C(C)(C)C)s3)c2-c2ccc(C(C)(C)C)s2)s1</smiles>

CMPs-TTT

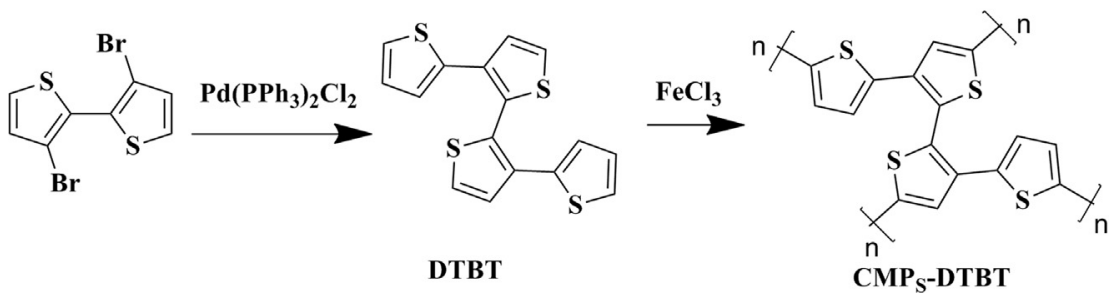

Scheme 1. Synthetic pathway toward the polythiophene networks CMPs-TTT and CMPs-DTBT. 
could be possibly due to the higher conformational flexibility of polythiophene [15]. At low pressure, both polymers exhibited little microporous structure, and at high pressure, the $\mathrm{N}_{2}$ adsorption branch shows a rapid increase which is a typical feature for macroporous system. This might be explained by assuming a collapse of the loose nanoparticulate structure, which yields smaller and ill-defined interstitial voids [32].

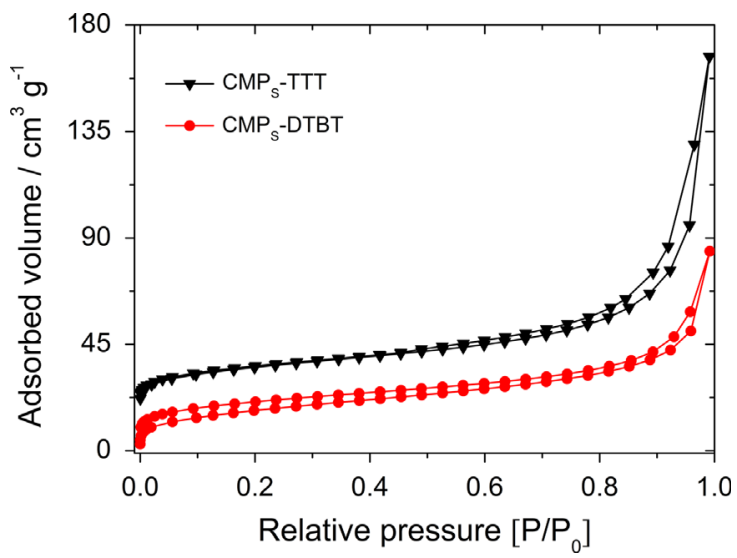

Fig. 2. Nitrogen adsorption-desorption isotherms of CMPs-TTT and CMPs-DTBT networks measured at $77 \mathrm{~K}$. The curve of CMPs-TTT was shifted vertically by $20 \mathrm{~cm}^{3} \mathrm{~g}^{-1}$ for clarity.
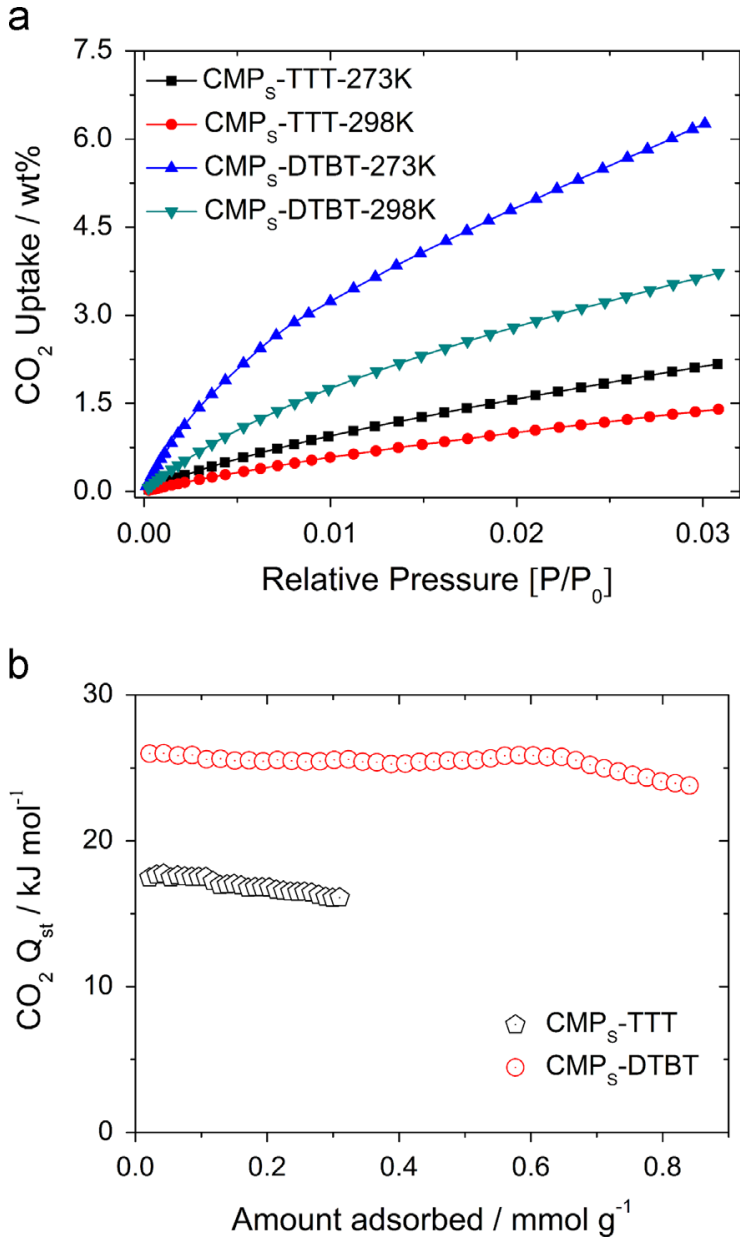

Fig. 3. (a) $\mathrm{CO}_{2}$ adsorption isotherms of CMPs-TTT and CMPs-DTBT at $273 \mathrm{~K}$ and $298 \mathrm{~K}$ (1.0 bar). (b) Variation of $\mathrm{CO}_{2}$ isosteric enthalpies with the adsorbed amounts.
The $\mathrm{CO}_{2}$ uptake of the polythiophene networks were measured up to 1.0 bar at $273 \mathrm{~K}$ and $298 \mathrm{~K}$ shown in Fig. 3a. It is interesting that CMPs-DTBT has the significantly more $\mathrm{CO}_{2}$ adsorbed than CMPs-TTT. The $\mathrm{CO}_{2}$ uptake of CMPs-DTBT is $6.26 \mathrm{wt} \%$, however, CMPs-TTT is only $2.17 \mathrm{wt} \%$ at $273 \mathrm{~K}, 1 \mathrm{bar}$, and the gap is 2.88 times. When measurement at $298 \mathrm{~K}, 1.0 \mathrm{bar}$, CMPs-DTBT is $3.72 \mathrm{wt} \%$, 2.65 times than that of CMPs-TTT (1.40 wt\%). It should be point out that the two networks have identical chemical constitution, polymerization process, and similar BET area and pore structure. The $\mathrm{CO}_{2}$ isosteric heat of sorption (Qst) was calculated at $273 \mathrm{~K}$ and $298 \mathrm{~K}$ based on the Clausius-Clapeyron equation shown in Fig. 3b. It can be observed that the isosteric enthalpies of CMPs-DTBT keep almost stable, and it is still above $25 \mathrm{~kJ} \mathrm{~mol}^{-1}$ when the loading increased to $0.7 \mathrm{mmol} \mathrm{g}^{-1}$, then exhibits negligible decrease when the loading is $0.8 \mathrm{mmol} \mathrm{g}^{-1}$, however the Qst of CMPs-TTT is less than $18 \mathrm{~kJ} \mathrm{~mol}^{-1}$ at the whole sorption range.

The UV-vis absorption spectra of CMPs-TTT and CMPs-DTBT were measured in solid state and shown in Fig. 4a. Optical characterization of the two polymers revealed that they had different aggregated morphology. CMPs-TTT demonstrated a pronounced
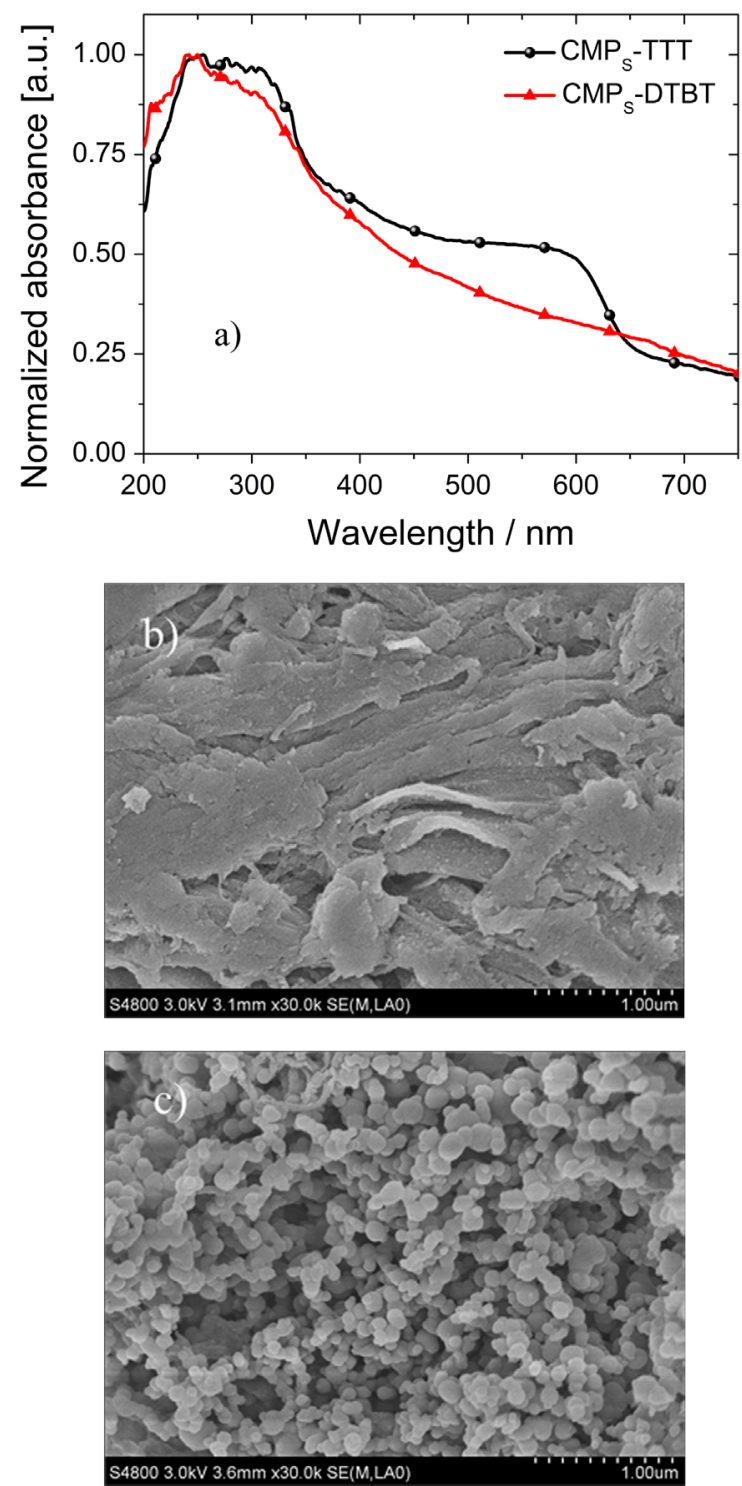

Fig. 4. (a) Normalized UV-vis absorption spectra of the two polythiophene networks. (b) and (c) SEM images of CMPs-TTT and CMPS-DTBT, respectively. (For interpretation of the references to color in this figure legend, the reader is referred to the web version of this article.) 
absorption platform from approximately $450 \mathrm{~nm}$ to $630 \mathrm{~nm}$ which can be attributed to the increased $\pi-\pi$ stacking and extension of conjugation over two dimensions in the solid state compared to CMPs-DTBT. Enhanced layer by layer interaction in the solid state can cause a significant red shift in the absorption spectra compared to that of the amorphous samples [33]. CMPs-DTBT showed typical UV-vis spectra, just as other reported conjugated microporous polymers. This discrepancy can explain why the two polymers have the identical chemical constitution but have different appearance (CMPs-TTT: dark red; CMPs-DTBT, brown). The FE-SEM images in Fig. 4b and c and TEM (Fig. S1) confirmed again that CMPs-TTT and CMPs-DTBT had the different aggregated morphology. The quasicoplanar and $\alpha$-thiophene chemical oxidative regioselective polymerization of TTT block made it facile to form large layer by layer stacking [30]. The pseudo-tetrahedral 3D conjugated architecture made DTBT to form amorphous stacking [31]. This different aggregated morphologies which have different surface energies resulted in the discrepancy of $\mathrm{CO}_{2}$ uptake capacities and sorption isosteric enthalpies for the two polythiophene isomers.

\section{Conclusions}

In summary, two conjugated porous polymers with different steric configuration thiophene-based building blocks were prepared at the same polymerization process. The two polymers have almost equal BET surface area, however, the $\mathrm{CO}_{2}$ uptake capacity of CMPs-DTBT is 2.88 times and 2.65 times higher than that of CMPsTTT at $273 \mathrm{~K}$ and $298 \mathrm{~K}$ (1.0 bar), respectively. UV-vis spectra, FE-SEM and TEM images showed CMPs-TTT and CMPs-DTBT having the different aggregated morphologies, which are the main reason that the polymers exhibit different $\mathrm{CO}_{2}$ uptake capacity although they have the identical chemical constitution. This work demonstrates that by design of initial monomer with specific geometries can change the polymer aggregated morphology which could influence the gas isotherms enthalpies and adsorption capacity, in other words at the same condition the gas adsorption capacity depends not only on the high BET area, but also on the aggregated morphology of the material.

\section{Acknowledgments}

This work was supported by the National Natural Science Foundation of China $(21274161,51173199)$, Ministry of Science and Technology of China (2010DFA52310), Chinese Academy of Sciences (KGCX2-YW-399+9-2), Department of Science and Technology of Shandong Province (2010GGC10345), Shandong Provincial Natural Science Foundation (ZR2011BZ007), and Qingdao Municipal Science and Technology Program (11-2-4-22-hz).

\section{Appendix A. Supporting information}

Supplementary data associated with this article can be found in the online version at http://dx.doi.org/10.1016/j.jssc.2013.12.025.

\section{References}

[1] D.M. D’Alessandro, B. Smit, J.R. Long, Angew. Chem. Int. Ed. 49 (2010) 6058-6082.

[2] Y.S. Bae, R.Q. Snurr, Angew. Chem. Int. Ed. 50 (2011) 11586-11596.

[3] H. Yang, Z. Xu, M. Fan, R. Gupta, R.B. Slimane, A.E. Bland, I. Wright, J. Environ. Sci. 20 (2008) 14-27.

[4] R. Banerjee, A. Phan, B. Wang, C. Knobler, H. Furukawa, M. O’Keeffe, O.M. Yaghi, Science 319 (2008) 939-943.

[5] S. Bourrelly, P.L. Llewellyn, C. Serre, F. Millange, T. Loiseau, G. Ferey, J. Am. Chem. Soc. 127 (2005) 13519-13521.

[6] A. Arenillas, K.M. Smith, T.C. Drage, C.E. Snape, Fuel 84 (2005) 2204-2210.

[7] R.E. Morris, P.S. Wheatley, Angew. Chem. Int. Ed. 47 (2008) 4966-4981.

[8] J.R. Li, Y. Ma, M.C. McCarthy, J. Sculley, J. Yu, H.K. Jeong, P.B. Balbuena, H.C. Zhou, Coord. Chem. Rev. 255 (2011) 1791-1823.

[9] B. Arstad, H. Fjellvåg, K.O. Kongshaug, O. Swang, R. Blom, Adsorption 14 (2008) $755-762$.

[10] R. Dawson, E. Stoeckel, J.R. Holst, D.J. Adams, A.I. Cooper, Energy Environ. Sci 4 (2011) 4239-4245

[11] M.G. Rabbani, T.E. Reich, R.M. Kassab, K.T. Jackson, H.M. El-Kaderi, Chem. Commun. 48 (2012) 1141-1143.

[12] Y. Luo, B. Li, W. Wang, K. Wu, B. Tan, Adv. Mater. 24 (2012) 5703-5707.

[13] R. Dawson, L.A. Stevens, T.C. Drage, C.E. Snape, M.W. Smith, D.J. Adams, A.I. Cooper, J. Am. Chem. Soc. 134 (2012) 10741-10744.

[14] N.B. McKeown, B. Gahnem, K.J. Msayib, P.M. Budd, C.E. Tattershall, K. Mahmood, S. Tan, D. Book, H.W. Langmi, A. Walton, Angew. Chem. Int. Ed. 45 (2006) 1804-1807.

[15] N.B. McKeown, P.M. Budd, Chem. Soc. Rev. 35 (2006) 675-683.

[16] X. Zou, H. Ren, G. Zhu, Chem. Commun. 49 (2013) 3925-3936.

[17] L. Chen, Y. Honsho, S. Seki, D. Jiang, J. Am. Chem. Soc. 132 (2010) 6742-6748.

[18] A.I. Cooper, Adv. Mater. 21 (2009) 1291-1295.

[19] A. Li, R.F. Lu, Y. Wang, X. Wang, K.L. Han, W.Q. Deng, Angew. Chem. Int. Ed. 49 (2010) 3330-3333.

[20] J. Weber, A. Thomas, J. Am. Chem. Soc. 130 (2008) 6334-6335.

[21] S. Yuan, S. Kirklin, B. Dorney, D.J. Liu, L. Yu, Macromolecules 42 (2009) 1554-1559.

[22] Q. Chen, J.X. Wang, Q. Wang, N. Bian, Z.H. Li, C.G. Yan, B.H. Han, Macromolecules 44 (2011) 7987-7993.

[23] J. Schmidt, J. Weber, J.D. Epping, M. Antonietti, A. Thomas, Adv. Mater. 21 (2009) 702-705.

[24] Q. Chen, M. Luo, P. Hammershoj, D. Zhou, Y. Han, B.W. Laursen, C.G. Yan, B.H. Han, J. Am. Chem. Soc. 134 (2012) 6084-6087.

[25] A.P. Katsoulidis, S.M. Dyar, R. Carmieli, C.D. Malliakas, M.R. Wasielewski, M.G. Kanatzidis, J. Mater. Chem. A 1 (2013) 10465-10473.

[26] A.P. Katsoulidis, M.G. Kanatzidis, Chem. Mater. 24 (2012) 471-479.

[27] A.P. Katsoulidis, M.G. Kanatzidis, Chem. Mater. 23 (2011) 1818-1824.

[28] H. Frost, T. Duren, R.Q. Snurr, J. Phys. Chem. B. 110 (2006) 9565-9570.

[29] A.R. Millward, O.M. Yaghi, J. Am. Chem. Soc. 127 (2005) 17998-17999.

[30] T. Benincori, V. Bonometti, F.D. Angelis, L. Falciola, M. Muccini, P.R. Mussini, T. Pilati, G. Rampinini, S. Rizzo, S. Toffanin, F. Sannicolo, Chemistry 16 (2010) 9086-9098.

[31] S. Karpe, A. Cravino, P. Frère, M. Allain, G. Mabon, J. Roncali, Adv. Funct. Mater. 17 (2007) 1163-1171.

[32] B. Kiskan, J. Weber, ACS Macro. Lett 1 (2012) 37-40.

[33] X. Guo, S.R. Puniredd, M. Baumgarten, W. Pisula, K. Mullen, J. Am. Chem. Soc 134 (2012) 8404-8407. 